Short Research Paper

\title{
Oral Piercing and Oral Diseases: A Short Time Retrospective Study
}

\section{Francesco Inchingolo1,4凶, Marco Tatullo2,4, Fabio M. Abenavoli ${ }^{3}$, Massimo Marrelli4, Alessio D. Inch- ingolo5, Antonio Palladino ${ }^{1}$, Angelo M. Inchingolo 6 , Gianna Dipalma ${ }^{4}$}

1. Department of Dental Sciences and Surgery, University of Bari, Bari, Italy

2. Department of Basic Medical Sciences, University of Bari, Bari, Italy

3. Department of "Head and Neck Diseases", Hospital "Fatebenefratelli", Rome, Italy

4. Department of Maxillofacial Surgery, Calabrodental, Crotone, Italy

5. Department of Dental Sciences and Surgery, Dental School, Bari, Italy

6. Department of Surgical, Reconstructive and Diagnostic Sciences, University of Milano, Milano, Italy

Corresponding author: Prof. Francesco INCHINGOLO, Piazza Giulio Cesare - Policlinico 70124 - Bari. E-mail: f.inchingolo@doc.uniba.it. Tel.: 00390805593343 - Infoline: 00393312111104.

(C) Ivyspring International Publisher. This is an open-access article distributed under the terms of the Creative Commons License (http://creativecommons.org/ licenses/by-nc-nd/3.0/). Reproduction is permitted for personal, noncommercial use, provided that the article is in whole, unmodified, and properly cited.

Received: 2011.07.27; Accepted: 2011.10.03; Published: 2011.10.18

\begin{abstract}
Body piercing indicates the puncturing of a part of the body in which jewelry may be worn. In recent years, oral piercing is increasingly popular especially among young people. Body piercing has to be considered as a surgical procedure to all intents and purposes and, as such, has to be performed only by qualified personnel able to assure high standards of professionalism in facilities subject to sanitary inspections.

The aim of the present work is to verify what risks patients may be exposed to and what complications may occur after a healthcare professional performs oral piercing.

Our retrospective study includes 108 patients (74 males and 34 females) aged between I 4 and 39 years, who had oral piercing done $12 \pm 4$ months earlier. All the patients underwent clinical examination to reveal the possible presence of late complications. After piercing, none of the 108 patients developed widespread complications.

Although all patients said they had followed the piercers' instructions, $96 \%$ of them reported postoperative local complications such as bleeding within 12 hours of piercing (90\%), perilesional edema for $3 \pm 2$ days after piercing surgery $(80 \%)$, and persistent mucosal atrophy $(70 \%)$.
\end{abstract}

Key words: Oral Piercing; Oral diseases; Complications of oral piercing.

\section{Introduction}

Body piercing indicates the puncturing of a part of the body in which jewelry may be worn. In recent years, oral piercing is increasingly popular especially among young people. ${ }^{1}$ The main reason that leads the young people to undergo piercing procedures is the pursuit of a form of body adornment, which has to be fashionable. Other possible reasons are: religion, fashion, tradition, rituals of belonging to an ethnic or social group or, the will to distinguish oneself from the other individuals and to rise above the group. ${ }^{2}$
$60 \%$ of teenagers have a piercing, mostly girls, aged between 15 and 19 years. However, oral piercing is especially prevalent in the male population.

Body piercing has to be considered as a surgical procedure to all intents and purposes and, as such, has to be performed only by qualified personnel able to assure high standards of professionalism in facilities subject to sanitary inspections. Besides, it would be opportune to provide regular follow-up of patients. ${ }^{1}$ Young people are often poorly informed about 
the risks they are exposed to after intraoral piercing, but even healthcare professionals often have a limited knowledge of risks and complications that may arise after this surgical procedure.

Therefore, the aim of the present work is to verify which risks patients are concretely exposed to and which complications may occur after a healthcare professional performs oral piercing.

\section{Materials and methods}

The present study includes one hundred and eight patients (74 males and 34 females) aged between 14 and 39 years, who presented with oral piercing done $12 \pm 4$ months earlier. In addition, we closely analyzed data from patients who had tongue piercing in order to analyze the clinical and functional alterations of the tongue of patients.

Patients were asked the reason why they decided to undergo this procedure; the subjects were randomly recruited and distinguished according to where the piercing is located.

After initial counseling, patient medical history was analyzed to identify useful information that could reveal the onset of intraoperative and postoperative complications. Finally, the patients underwent clinical examination to reveal the possible presence of late complications.

\section{Results}

$70 \%$ of the recruited subjects decided to pierce their body as a form of decoration, $15 \%$ as a memory of a particular event and $15 \%$ as a sign of identification.

$45 \%$ of patients had a tongue piercing; $35 \%$ had a labret piercing; $10 \%$ had a lip piercing; $5 \%$ had a piercing on the right side of the upper lip; $5 \%$ had a tongue piercing and a labret piercing. (Fig. 1)

After piercing, none of the 108 patients developed widespread complications.

Although all patients said they had followed the piercer's indications, $96 \%$ of them reported postoperative local complications such as bleeding within 12 hours of piercing $(90 \%)$, perilesional edema for $3 \pm 2$ days after piercing surgery (80\%), persistent mucosal atrophy $(70 \%)$, enamel abrasions $(30 \%)$, enamel fractures $(30 \%)$, gingival recession $(25 \%)$, erythematous palatal mucosa $(15 \%)$, dentine hypersensitivity $(15 \%)$. All patients with tongue piercing have reported a transient alteration in taste, probably associated with the presence of a metallic foreign body in the oral cavity or with blood and serum leakage during the healing process of tissues. The taste disturbance lasted on average 7-10 days. In addition, two patients re- ported that they had to remove the piercing for a large swelling developed on the mucosa of the tongue.

No neoplastic alteration has been clinically detected.

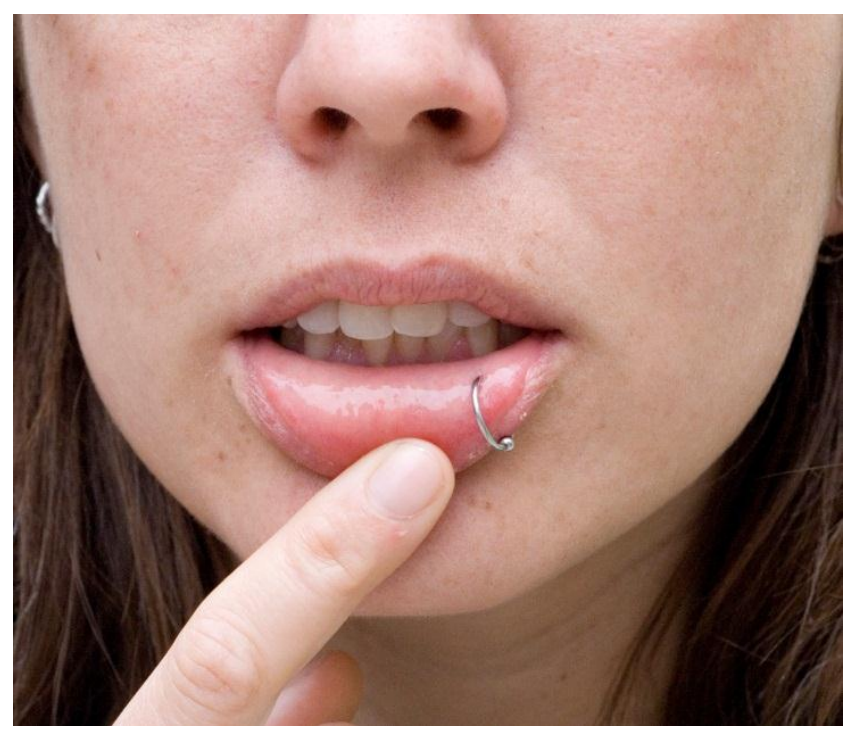

Figure I: A lower labial piercing in a young female

\section{Discussion}

The analysis of results shows that the area that most of the recruited patients prefer to pierce is the tongue: this seems to be in agreement with the recent literature. ${ }^{1}$ In fact, it is important to underline that this area is at highest risk for hemorrhagic complications, because of the extensive vascularization in the tongue.

From a dental point of view, oral piercings and tongue piercing in particular are not harmless fashion trends, as they are often associated with local and systemic complications. Complications may be immediate or delayed, according to the onset. ${ }^{3}$

The local risks are: ${ }^{2,4-7}$

- Oral mucosal lesions: tongue, gums and palate are the most frequently affected areas;

- Possible tooth loss, particularly in the anterior mandibular region;

- Dentine hypersensitivity and periodontitis;

- Dental fissures or extensive gingival recession;

- Hemorrhage, hematoma and infection because the piercing was in continuous contact with food and saliva. ${ }^{1}$

- Phonation and masticatory disorders;

- Tooth migration;

- Streptococcal pharyngitis;

- Presence of unpleasant sensations such as itch, ache and pain; 
- Motor and sensitive nerve lesions: nerve damage is more frequent in case of dorsolateral tongue piercing. These lesions involve alterations such as dysgeusia for a few days or more.

The systemic risks are:

- Cross-transmission of infectious diseases like hepatitis B, C or D and AIDS. 2,8

- Endocarditis secondary to Staphylococcus Epidermidis and to several infectious agents like Haemophilus Aphrophilus. Therefore, an antibiotic prophylaxis should be used in subjects at risk, before piercing. ${ }^{1,2,8}$

- Bacteremia and sepsis with generalized symptoms and high fever. As a consequence of oral piercing, the literature reports a case of Ludwig's angina and connective tissue inflammation, which rapidly spreads to the sublingual, submandibular and submental spaces, with deglutition, respiration and phonation disorders and major life-threatening risk. ${ }^{1,2,8}$

- Allergic reactions to the metal used (especially nickel). ${ }^{1,2,8}$

- Eczematous skin rash. 1,2,8

In our study, no systemic complications were identified. However, it seems very important to underline that body piercing should always be done by medical staff in a clean room. As a matter of fact, it is clear that the risk of systemic complications is significantly higher when body piercing is done by untrained personnel without sanitary inspections.

On clinical examination, almost all the patients of our study group reported or presented with local complications. In particular, bleeding and perilesional edema are highly prevalent right after piercing surgery. From a clinical point of view, one of the most frequent complications encountered at least 12 months after surgery is atrophy of perilesional mucosa, probably because of a chronic trauma. This trauma seems to underlie palate erythema, which was encountered in approximately $33 \%$ of patients with tongue piercing. The most frequently encountered complications in subjects with lower- or upper-lip piercings are gingival recessions, enamel fractures and dental abrasions.

\section{Conclusions}

Patients with tooth piercing have to be informed about the risk of local and systemic complications; therefore, awareness campaigns are necessary for dentists and patients. Several dental associations such as ADA (American Dental Association), BDA (British Dental Association), IDA (Irish Dental Association) and SSO (Swiss Dental Association) have already pronounced against oral piercing through official documents and guidelines.

A series of recommendations should be given to people undergoing this procedure, in order to avoid all these risks and reduce to a minimum the onset of postoperative complications: $5-7$

- Have a cold liquid diet for the first 24 hours, and then a soft food diet.

- Ice the external part for 30 minutes at intervals of 45 minutes for a total $4 / 5$ applications a day, to reduce the edema occurring in the first stage of healing. The swelling reduces after 24 hours and disappears after about 5 days.

- Do not use any type of oral rinse for the first 24 hours; then $4 / 5$ rinses a day with $0,12 \%$ chlorhexidine for 10 days.

- Limit alcohol, cigarettes and caffeine, at least for the first few days: they could increase swelling, bleeding, pain or compromise the physiological process of epithelial cell turnover in the oral mucosa.

- Replace the oral piercing jewelry with something smaller which will reduce irritation of the oral cavity, once the lesion has healed.

- Avoid chewing tobacco, nails and gums to prevent further microlesions of the oral mucosa during soft tissue healing.

- Avoid speaking too much, or beating the jewelry against dental hard tissues: the mouth already suffers a severe trauma while speaking and eating.

- Take particular care of oral hygiene and brush the jewelry with a soft toothbrush, which should be done very gently when the lesion is still healing in order to reduce plaque formation around the oral piercing. As a matter of fact, particular attention should be paid in maintaining personal health: it is important to be patient during the entire healing process, even if the piercing seems to have healed earlier than expected.

- Regularly check oral and perioral piercings to avoid infections in such areas.

\section{Authors' Contributions}

FI and FMA participated in the surgical treatment and in the follow-up examinations. MT and AP drafted the manuscript and revised the literature sources. MM and GD participated in the follow-up examinations.

ADI revised the literature sources. AMI and AP managed the data collection and contributed to writ- 
ing the paper. All authors read and approved the final manuscript.

\section{Consent Statement}

Written informed consent was obtained from the patient for publication of this case report and accompanying images.

\section{Conflict of Interest}

The authors have declared that no conflict of interest exists.

\section{References}

1. Jeger F, Lussi A, Zimmerli B. Oral jewelry: a review. Schweiz Monatsschr Zahnmed. 2009;119(6):615-31.

2. Küstner E.C, Travé I.B, Rengifo S.V, Carabaño T.G, Iglesias HV, Llabrés XR. Estética y cultura: patología bucal asociada a ciertas modas "actuales" (tatuajes, perforaciones bucales, etc.). Med Oral 2003;8:197-206.

3. Ziebolz D, Stuehmer C, van Nüss K, Hornecker E, Mausberg RF. Complications of tongue piercing: a review of the literature and three case reports. J Contemp Dent Pract. 2009 Nov 1;10(6):E065-71.

4. Kapferer I, Berger K, Stuerz K, Beier US. Self-reported complications with lip and tongue piercing. Quintessence Int. 2010;41:731-737.

5. Hickey BM, Schoch EA, Bigeard L, Musset AM. Complications following oral piercing. A study among 201 young adults in Strasbourg, France. Community Dent Health. 2010 Mar;27(1):35-40.

6. Pires IL, Cota LO, Oliveira AC, Costa JE, Costa FO. Association between periodontal condition and use of tongue piercing: a case-control study. J Clin Periodontol. 2010 Aug 1;37(8):712-8.

7. Hupp WS. Palatal Erythema. J Am Dent Assoc, 2009; 140(5): 555-557

8. Akhondi H and Ali R. Rahimi Haemophilus aphrophilus Endocarditis after Tongue Piercing. Emerg Infect Dis. 2002; 8(8): 850-851. 